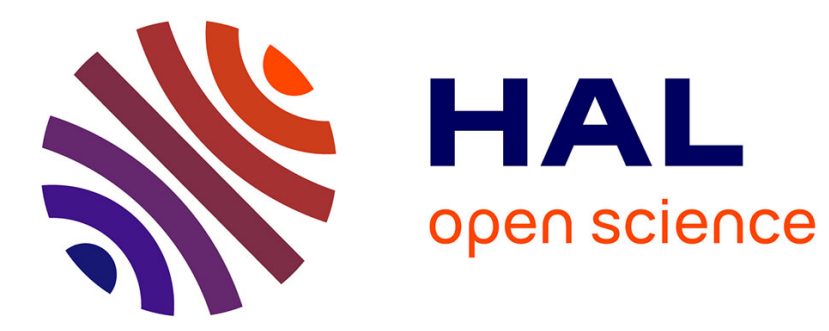

\title{
Multiscale Analysis of the Roughness Effect on Lubricated Rough Contact
}

Ibrahim Demirci, Sabeur Mezghani, Mohammed Yousfi, Mohamed El Mansori

\section{To cite this version:}

Ibrahim Demirci, Sabeur Mezghani, Mohammed Yousfi, Mohamed El Mansori. Multiscale Analysis of the Roughness Effect on Lubricated Rough Contact. Multiscale Analysis of the Roughness Effect on Lubricated Rough Contact, 2014, 136, pp.8. 10.1115/1.4025222 . hal-00880991

\section{HAL Id: hal-00880991 \\ https://hal.science/hal-00880991}

Submitted on 7 Nov 2013

HAL is a multi-disciplinary open access archive for the deposit and dissemination of scientific research documents, whether they are published or not. The documents may come from teaching and research institutions in France or abroad, or from public or private research centers.
L'archive ouverte pluridisciplinaire HAL, est destinée au dépôt et à la diffusion de documents scientifiques de niveau recherche, publiés ou non, émanant des établissements d'enseignement et de recherche français ou étrangers, des laboratoires publics ou privés. 


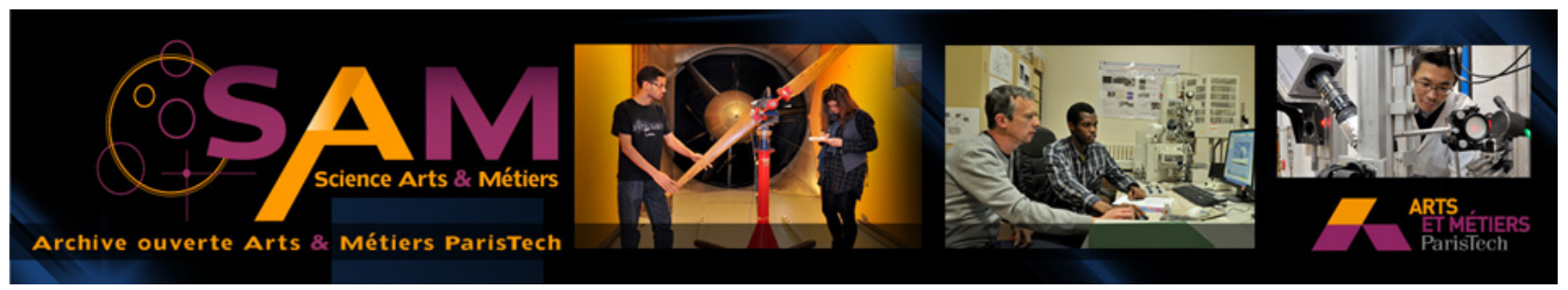

\section{Science Arts \& Métiers (SAM)}

is an open access repository that collects the work of Arts et Métiers ParisTech researchers and makes it freely available over the web where possible.

This is an author-deposited version published in: http://sam.ensam.eu

Handle ID: .http://hdl.handle.net/10985/7474

\section{To cite this version :}

Ibrahim DEMIRCI, Sabeur MEZGHANI, Mohammed YOUSFI, Mohamed EL MANSORI Multiscale Analysis of the Roughness Effect on Lubricated Rough Contact - Multiscale Analysis of the Roughness Effect on Lubricated Rough Contact - Vol. 136, p.8 - 2014 


\title{
Ibrahim Demirci \\ e-mail: ibrahim.demirci@ensam.eu \\ Sabeur Mezghani \\ e-mail: sabeur.mezghani@ensam.eu \\ MSMP, \\ Arts et Métiers Paristech, \\ Multiscale Analysis of the Roughness Effect on Lubricated Rough Contact
}

Rue Saint Dominique, BP 508

Châlons en Champagne 51006, France

Mohammed Yousfi

Direction de l'Ingénierie Mécanique,

Renault S.A.S,

67 Rue Des Bons Raisins,

Rueil Malmaison 92500, France

e-mail: mohammed.yousfi@renault.com

\author{
Mohamed El Mansori \\ MSMP, \\ Arts et Métiers Paristech, \\ Rue Saint Dominique, BP 508, \\ Châlons en Champagne 51006, France \\ e-mail: Mohamed.elmansori@ensam.eu
}

\begin{abstract}
Determining friction is as equally essential as determining the film thickness in the lubricated contact, and is an important research subject. Indeed, reduction of friction in the automotive industry is important for both the minimization of fuel consumption as well as the decrease in the emissions of greenhouse gases. However, the progress in friction reduction has been limited by the difficulty in understanding the mechanism of roughness effects on friction. It was observed that micro-surface geometry or roughness was one of the major factors that affected the friction coefficient. In the present study, a new methodology coupling the multiscale decomposition of the surface and the prediction of the friction coefficient by numerical simulation was developed to understand the influence of the scale of roughness in the friction coefficient. In particular, the real surface decomposed in different roughness scale by multiscale decomposition, based on ridgelets transform, was used as input into the model. This model predicts the effect of scale on mixed elastohydroynamic point contact. The results indicate a good influence of the fine scale of surface roughness on the friction coefficient for full-film lubrication as well as a beginning of improvement for mixed lubrication. [DOI: 10.1115/1.4025222]
\end{abstract}

Keywords: roughness scale, surface texture, lubrication, friction

\section{Introduction}

Friction coefficient, which is sometimes necessary (to walk, hold an object, brake, etc.), is harmful in most cases. In particular, the friction coefficient determines the efficiency of machine components and the power loss in contact. For example, in the automotive industry, the reduction of friction in the engine would reduce fuel consumption, thereby reducing the emissions of greenhouse gases. Thus, determining the appropriate friction is as important as determining the film thickness in the contact and is an important research subject. Several studies have been conducted to determine laws for predicting the film thickness. The film thickness can be accurately determined by the famous Dowson and Higginson law [1] as well as the Hamrock and Dowson formula [2] for smooth surfaces. With the development of numerical and experimental tools, several studies have also made progress in understanding the effects of surface roughness on the film thickness [3-5]. However, studies on the development of the laws of friction predictions are very few in comparison to the impressive number of studies conducted on film thickness. The complexity of lubricant behavior in a high-pressure region (in the contact area) and the difficulty to incorporate non-Newtonian law in a numerical model for point or elliptical contacts could be the possible reasons for the small number of studies on friction laws. However, some studies [6-9] used the non-Newtonian rheological behavior in line contact. Nevertheless, friction has been vaguely studied, while there has not been any attempt to study the friction laws. The studies conducted by Evans and Johnson [10] and Olver and Spikes [11] have provided clues regarding the characteristic parameters for determining the friction. One of the few attempts to determine a predictive friction law was proposed by Jacod $[12,13]$. A general friction prediction law was defined for smooth isothermal elliptic contact using numerical simulation. The authors assumed the Eyring non-Newtonian behavior and limiting shear stress models for the lubricant. The friction results on a

Contributed by the Tribology Division of ASME for publication in the JournaL OF TRIBOLOGY. Manuscript received October 24, 2012; final manuscript received July 21, 2013; published online September 23, 2013. Assoc. Editor: Robert L. Jackson. single generalized curve, which relates the friction to a shear stress. Thus, the authors conclude that a unifying mechanism governed the friction in EHL contacts $[12,13]$.

Most of the above mentioned studies have been conducted for ideally smooth surfaces. However, microsurface geometry or roughness was found to be one of the major factors affecting the friction coefficient. Nevertheless, progress in friction reduction has been limited by the difficulty in understanding the mechanism of roughness effects on friction, even though it is a crucial task for the industry (in particular, the automotive industry). Considerable effort has been made for several years to understand the role of surface topography on friction. There are two approaches for studying the influence of surface roughness in the flow of the lubricant: the stochastic and the deterministic approach. The first approach is based on probabilistic considerations. Indeed, the roughness is taken into account in the Reynolds equation by flow factors [14-16]. The second approach takes into account the roughness in the equation of the film thickness. However, the numerical solution in this case requires the use of a very fine mesh. Thus, the study was limited mainly to point or line contacts. The first studies were devoted to simple geometries by modeling a single asperity [17] or a sinusoidal profile with specific amplitude and wavelength [18-20]. Based on this approach, the effect of reducing the amplitude of roughness has been studied. The results help to define dimensionless parameters governing the amplitude reduction $[21,22]$ and draw a curve quantifying the magnitude of deformations $[5,23,24]$. In recent times, the research conducted by Rich and Villechaise [25] noted that surface waviness had a more significant impact on pressure distribution than on the peak valley amplitude. Another approach, based on the principle of homogenization has also been used to study the influence of roughness on the lubricated contact. This method uses multiple scales. Originally proposed by Elrod [26], the method has been further studied by several authors [27-30]. The analysis is based on the description of simplified surface profiles, for example, of periodic patterns, thereby making it suitable for the study of textured surfaces. However, this technique was limited to the study of simple parameters like shape, orientation, density of pattern, and anisotropy of surface texture on film thickness and pressure distributions 
[31-35]. Thus, the friction coefficient is rarely studied and real surfaces are used infrequently owing to their complexity. However, some authors $[36,37]$ used real surfaces to study the friction coefficient. They studied the friction reduction by the effect of lubricant additives [36]. They also examined the influence of different surface patterns on the friction change during the transition from EHL to boundary lubrication [37]. The authors of the present study commenced the research by focusing on the influence of surface roughness on the friction coefficient $[38,39]$. They examined the influence of the fractal dimension of surfaces [38]. The surfaces are obtained by virtual texturing methods. In another work, the same authors studied the influence of the groove texture patterns [39] on the friction coefficient. Finally, Jacod [13] attempted to define a friction predicting law, but not for a real surface. He used simple surfaces with longitudinal roughness to provide a general formula for predicting the changes in friction in comparison to the smooth surfaces. This formula depends on the wavelength and a parameter characterizing the response of the contact pressure variations [13]. There are very few researches that have contributed to the study of friction for real surfaces, in particular, the study of the influence of each scale of surface on friction.

The present study is aimed at understanding the influence of the roughness scale on the friction coefficient by means of numerical simulations in EHL point contacts. The non-Newtonian rheological model was used in the simulation. The real surface is decomposed in different roughness scale by multiscale decomposition based on ridgelets transform. Each component was taken into account in the film thickness equations. The numerical model uses the finite difference method. This model enables predicting the film thickness, pressure distribution, and friction coefficient for full-film EHL lubrication.

\section{Description of the Elastohydrodynamic Model}

A numerical model was developed to estimate the friction generated between rough surfaces. The model considered the real topography of the surfaces. The scope of this model is to qualitatively predict the friction coefficient obtained when the groove characteristics of surfaces are varied. The aim of this prediction is to optimize the friction performance.

2.1 Elastohydrodynamic Equations. The generalized Reynolds' equation introduced by Najji [40] has been used to estimate the pressure distribution, film thickness, and the friction coefficient. This equation has the advantage of not being restricted to a particular non-Newtonian law.

The following dimensionless variables are used in the generalized Reynolds' equation:

$$
\begin{aligned}
& X=\frac{x}{a_{h}}, \quad Y=\frac{y}{a_{h}}, \quad Z=\frac{z}{h}, \quad P=\frac{p}{p_{h}}, \quad \bar{\rho}=\frac{\rho}{\rho_{0}}, \quad \bar{\eta}=\frac{\eta}{\eta_{0}}, \\
& \mu=\frac{\mu}{\mu_{0}}, \quad H=\frac{h R}{a_{h}^{2}}, \quad \bar{\delta}=\frac{\delta R}{a_{h}^{2}}, \quad T=\frac{t u_{m}}{a_{h}}
\end{aligned}
$$

The resulting steady state equation in the dimensionless form is given by

$$
\begin{gathered}
\frac{\partial}{\partial X}\left\{\frac{\bar{\rho} H^{3}}{\lambda^{\prime}}\left(\frac{1}{\overline{\eta_{e}^{\prime \prime}}}-\frac{\overline{\eta_{e}}}{\overline{\eta_{e}^{\prime 2}}}\right) \frac{\partial P}{\partial X}\right\}+\frac{\partial}{\partial Y}\left\{\frac{\bar{\rho} H^{3}}{\lambda^{\prime}}\left(\frac{1}{\overline{\overline{\eta_{e}^{\prime \prime}}}}-\frac{\overline{\eta_{e}}}{\overline{\eta_{e}^{\prime} 2}}\right) \frac{\partial P}{\partial Y}\right\} \\
=\frac{\partial \bar{\rho} H\left(u_{2}-\frac{\overline{\eta_{e}}}{\overline{\eta_{e}^{\prime}}}\left(u_{2}-u_{1}\right)\right)}{\partial X}+\frac{\partial \bar{\rho} H}{\partial T}
\end{gathered}
$$

where $\lambda^{\prime}=\left(R^{2} \mu_{0} / p h a_{h}^{3}\right),\left(1 / \overline{\eta_{e}}\right)=\int_{0}^{1}(d Z / \bar{\eta}),\left(1 / \overline{\eta_{e}^{\prime}}\right)=\int_{0}^{1}(Z d Z / \bar{\eta})$ and $\left(1 / \overline{\eta^{\prime \prime}}\right)=\int_{0}^{1}\left(Z^{2} d Z / \bar{\eta}\right)$.
The effective viscosities could be calculated as considering the shear-thinning effect (Eyring fluid)

$$
\frac{1}{\bar{\eta}}=\frac{1}{\bar{\mu}} \frac{1}{\bar{\tau}_{m}} \sinh \left(\overline{\tau_{m}}\right)
$$

with $\overline{\tau_{m}}=\tau_{e} / \tau_{0}$, where, $\tau_{0}$ is a reference shear stress and $\tau_{e}=\sqrt{\tau_{x}^{2}+\tau_{y}^{2}}$ is the equivalent shear stress inside the lubricant film.

The lubricant's viscosity and density are assumed to depend on pressure. The Dowson and Higginson formula [1] (Eq. (3)) and Roelands law [41] (Eq. (4)) were used

$$
\bar{\rho}(P)=\left[1+\frac{0.6 \times 10^{-9} P \cdot p_{h}}{1+1.7 \times 10^{-9} P \cdot p_{h}}\right]
$$

where $\rho_{0}$ is the density at ambient pressure.

$$
\bar{\mu}(P)=\exp \left(\left(\ln \left(\mu_{0}\right)+9.67\right)\left(-1+\left(1+\frac{P \cdot p_{h}}{p_{r}}\right)^{Z_{r}}\right)\right)
$$

where $\mu_{0}$ is the viscosity at ambient pressure, $p_{r}$ is a constant equal to $1.96 \times 10^{8}$, and $Z_{r}$ is the pressure viscosity index.

Finally, the boundary condition $P=0$ and the cavitation $P(X, Y) \geq 0 \forall X, Y$ must be satisfied during the simulation.

The film thickness equation is given in dimensionless form by the following equation:

$$
H(X, Y, T)=H(T)+\frac{X^{2}}{2}+\frac{Y^{2}}{2}+\bar{\delta}(X, Y, T)-\overline{Z_{h}}(X, Y, T)
$$

where $\overline{Z_{h}}=\left(Z_{h} R / a_{h}^{2}\right)$ is the dimensionless height surface topography at each position $(X, Y)$ and $\bar{\delta}(X, Y, T)$ is the dimensionless surface deformation calculated by

$$
\bar{\delta}(X, Y, T)=\frac{2}{\pi^{2}} \iint_{\Omega_{c}+\Omega_{c h}} \frac{p\left(X^{\prime}, Y^{\prime}, T\right) d X^{\prime} d Y^{\prime}}{\sqrt{\left(X-X^{\prime}\right)^{2}+\left(Y-Y^{\prime}\right)^{2}}}
$$

The global force balance condition is given by

$$
\frac{2 \pi}{3}=\iint_{\Omega_{c}+\Omega_{c h}} p(X, Y, T) d X d Y \quad \forall T
$$

2.2 Numerical Procedure. In order to obtain the film pressure distribution, the Reynolds equation was solved by the finite difference method. A second order accuracy was used with respect to both space and time [42]. The discretized equation was solved by the Jacobi line relaxation [43]. The full-scale mixed EHL approach developed by $\mathrm{Hu}$ and Zhu [44] was used in the present study. In this approach, they used a unified equation system and solution method for both lubricated area and asperity contact simultaneously. The idea is based on the concept that the system of equations (Eqs. (1)-(7)) are applicable to entire solution domain, including the areas of asperity contact where $h=0$. In order to accelerate the solution convergence, the multigrid method [43] was used. The elastic deformation calculation was conducted by using Multi-Level-Multi-Integration [43]. At every iteration, the integral terms in the generalized Reynolds' equation were calculated using the solution obtained at the previous stage. A classical Newton-Raphson procedure was used to determine the shear stress and the effective viscosities. The solution domain was determined as $-2.5 \leq X \leq 1.5$ and $-2.0 \leq Y \leq 2.0$. The computational grid covering the domain consisted of equally spaced $513 \times 513$ or $1025 \times 1025$ nodes. This correspond to a spatial mesh of $d X=d Y=0.0078(512 \times 512)$ and $d X=d Y=0.0039$ $(1024 \times 1024)$, respectively. For transient state, NU2 scheme as 
described in Ref. [24] is used and $d T=d X$. Using rough surfaces in EHL simulation could yield localized asperity contact pressure peaks usually higher than the average EHL pressure. This results in high subsurface stress that exceeds the material yielding limit [45]. To limit the contact pressure, the elastic-perfectly plastic behavior of a material was approximately simulated by using a cutoff value, for example, the hardness of the material.

2.3 Model Validation. The present model for the mixed lubrication approach was compared to the sinusoidal wavy surface case used in Hu and Zhu's research [44]. It was observed that the same parameter and rolling velocity of $312.5 \mathrm{mms}^{-1}$ were chosen. Figure 1 depicts the pressure profile and the film thickness versus $x$-axis. A good agreement was found between the two models.

To improve the precision of the calculations, the amplitude reduction predictions for each of their scales (this parameter is described in Secs. 3 and 4) are done and give in a table. The ratio between the deformed amplitude $A_{d}$ and initial amplitude $A_{i}$ is calculated and compared to the relation done in Ref. [5] and value in Ref. [46].

Table 1 shows this comparison. $\nabla$ is a dimensional wavelength parameter which represents ratio between wavelength of the waviness and the operating conditions of the contact. Values from our simulation are in agreement with those of Ref. [5] and Ref. [46]. This test confirmed the validity of the model presented in the study.

\section{Multiscale Surface Roughness Characterization}

The multiscale characterization of engineering surfaces is pertinent to describe the surface features and irregularities at various wavelengths that compose the surface. The surface data was split into different frequency components and then characterized at each individual scale [47-51]. Wavelets are a kind of mathematical function that split data into different frequency components and then study each surface component with a resolution matched to its scale. Wavelets present advantages over the traditional methods in analyzing physical situations, in particular where the signal contains discontinuities and sharp spike-like surface roughness irregularities.

The honed surface texture mainly consists of two sets of straight, approximately parallel grooves placed stochastically, which appear at different angles to the cylinder axis. Thus, the ridgelets transform was used in the present study instead of the bidimensional continuous wavelets transform, as the former is more effective in representing linear surface patterns [50]. Herein, the 1D continuous wavelets transform were applied on the projections of the Radon transform $R_{f}$ of the surface data [52,53].

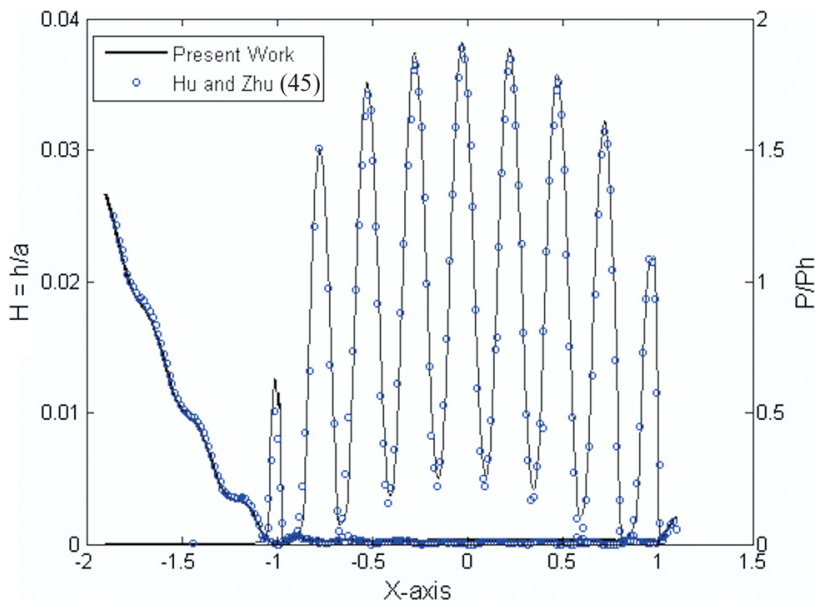

Fig. 1 Film thickness and pressure profile for validation of the present study compared to the research of Hu and Zhu [44]
The continuous ridgelets transform of function $f(x)$ is defined as [53]

$$
R_{f}(a, b, \theta)=\int_{\Re^{2}} \psi_{a, b, \theta}(r) f(r) d r
$$

where the ridgelet $\psi_{a, b, \theta}(r)$ is defined from a 1D wavelet-type function $\psi(r)$ as

$$
\psi_{a, b, \theta}(r)=a^{-1 / 2} \psi((x \cos \theta+y \sin \theta-b) / a)
$$

In the present study, the "Morlet 1D" wavelet is used in a simpler form as

$$
\psi(r)=\pi^{-1 / 4} e^{i w_{0} r} e^{-r^{2} / 2}
$$

The Morlet wavelet decomposition of a signal which contains the projected surface data by the Radon transform enables the identification of the multiscalar topographical features on the honed surface after an inverse ridgelet transformation [52].

The reconstructed surface at each scale $f_{a}$ is obtained using the following expression:

$$
f_{a}(r) \int_{0}^{2 \pi+\infty} \int_{-\infty} R_{f}(a, b, \theta) \psi_{a, b, \theta}(r) \frac{1}{a_{3}} d b \frac{d \theta}{4 \pi}
$$

\section{Results and Discussions}

The plateau honed surface was digitized with an optical interferometer apparatus. The obtained surface was decomposed at different scales using the ridgelet transform resulting into five surface components (Fig. 2). The lower scale corresponds to finer surface irregularity (Fig. 2(f)). The values $(1.92 \mathrm{~mm}, 0.96 \mathrm{~mm}$, $0.48 \mathrm{~mm}, 0.24 \mathrm{~mm}$, and $0.12 \mathrm{~mm}$ ) represent the value of the scale parameter associated to each surface component. This scale parameter can be interpreted as a pseudo-wavelength. The sum of these five surfaces (Fig. 2(b)-2(f)) reconstructs perfectly the original plateau-honed surface (Fig. 2(a)).

To study the scale effect of surface topography, a low scale was successively removed from the analyzed honed surface. This generates various surfaces with different finer roughness scale respectively $1.92,0.96,0.48,0.24,0.12 \mathrm{~mm}$ (Fig. 3). Figure $3(a)$ is the original surfaces whereas Fig. 3(b)-3(e) are original surface with one scale removed (for example, Fig. 3(b)=Fig. 3(a)-Fig. 2(b)). Generated surfaces were used as the input into the simulations via the film thickness equation (Eq. (5)). Several conditions were used for evaluating the contact parameters.

The smooth surface speeds varied between 0.5 and $2 \mathrm{~m} \cdot \mathrm{s}^{-1}$, while the rough surfaces (i.e. honed surface) was kept constant, so the slide to roll ratio is 2.0. The applied load $F_{N}$ was considered in the range of $10-100 \mathrm{~N}$. The materials properties were $E^{\prime}=219.78 \mathrm{GPa}$. The range of values corresponding to the Moes load and the lubricant parameters are $5<M<200$ and $5<L<12$.

The total friction averaged in time $\mu_{f}$ in mixed lubrication is evaluated by summing up the boundary friction contributed by the contacted areas and the traction in the hydrodynamic regions

$$
\mu_{f}=\frac{\iint_{\Omega_{c}} \tau_{c} d x d y+\iint_{\Omega_{c h}} \tau_{x} d x d y}{F_{N}}
$$

where $\tau_{c}$ is the shear stress between the contacting asperities at contact zone $\Omega_{\text {c. }} \tau_{x}$ is the shear stress of hydrodynamic films within the lubricated zone $\Omega_{c h}$. $\tau_{c}$ is considered to be the shear stress of the boundary film which occurs when the local film thickness is less than $5 \mathrm{~nm}$ in the present study. Hence $\tau_{c}$ can be determined by the Rabinowicz formula [54] 
Table 1 Amplitude reduction for each scale

\begin{tabular}{lcccc}
\hline \hline $\begin{array}{c}\text { Scale } \\
(\mathrm{mm})\end{array}$ & $\nabla=\lambda / a_{h} \sqrt{M / L}$ & $\begin{array}{c}\left(A_{d} / A_{i}\right) \text { from } \\
\text { Ref. [5] }\end{array}$ & $\begin{array}{c}\left(A_{d} / A_{i}\right) \text { from } \\
\text { Ref. [46] }\end{array}$ & $\begin{array}{c}\left(A_{d} / A_{i}\right) \text { from } \\
\text { our simulation }\end{array}$ \\
\hline 1.92 & 16.4 & 0.2588 & 0.28 & 0.28 \\
0.96 & 8.2 & 0.429 & 0.307 & 0.33 \\
0.48 & 4.1 & 0.61 & 0.7 & 0.68 \\
0.24 & 2.05 & 0.76 & 0.83 & 0.8 \\
0.12 & 1.025 & 0.86 & 0.9 & 0.88 \\
\hline \hline
\end{tabular}

$$
\tau_{c}=\sqrt{\tau_{S 0}^{2}+\left(\gamma_{s} p\right)^{2}}
$$

where $\tau_{S 0}$ is the initial shear strength of the boundary film. $\gamma_{s}$ is the pressure coefficient corresponding to the friction coefficient in boundary lubrication. In the present study, $\gamma_{s}$ and $\tau_{S 0}$ are equal to 0.1 and $2 \mathrm{MPa}$, respectively [37]. If the local film thickness is equal to zero, solid-to-solid contacts occur and the friction coefficient is assumed to be constant. It is equal to 0.25 in the present study. Finally, the mean in time of friction coefficient is presented in this work.
Figure 4 depicts the evolution of friction coefficient as a function of finer roughness scale parameters for $u_{1}=2 \mathrm{~m} \cdot \mathrm{s}^{-1}$. Evolution of the friction coefficient is quite different depending on the normal force. For $10 \mathrm{~N}$, the friction coefficient is low for a low scale (rough surfaces) and increases when the scale parameters increase (surface becomes less irregular). This small value of the friction coefficient justifies the full elastohydrodynamic regime. For $40 \mathrm{~N}$, the friction coefficient is low for small value of scale (rough surface), then it increases when the scale increase until reaching a maximum value for the penultimate level. Finally, the friction coefficient decrease at the highest scale (smooth surface). Two transitions in friction coefficient are observed when scale decreases: the first one, transition from full-film to mixed lubrication (friction coefficient is over 0.1 ), the second one, transition from mixed lubrication to full-film. For $100 \mathrm{~N}$, the coefficient of friction shows a tendency similar but higher value than to $40 \mathrm{~N}$. The friction coefficient increases until a maximum value and decrease. Two transitions are also observed. However, the transition from mixed lubrication to full film (fiction coefficient less than 0.1 ) occurs at a smaller scale than for $40 \mathrm{~N}$.

To explain this evolution, the contact load ratio is studied. This represents the ratio between asperities contact area and the total contact area. Zero percent means full-film lubrication whereas

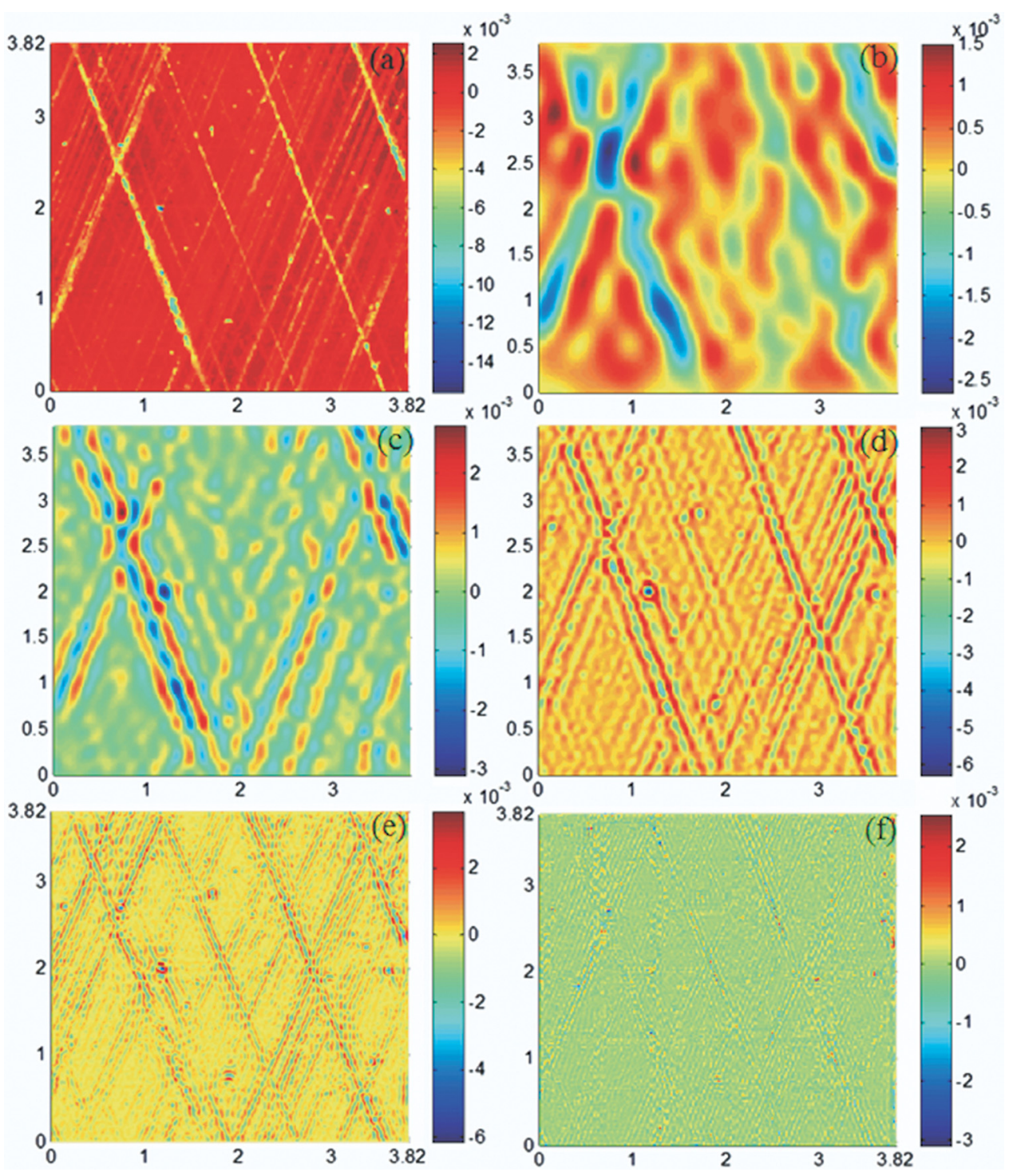

Fig. 2 (a) Original plateau-honed surface and its decomposition at different scales level from waviness to roughness with (b) $1.92 \mathrm{~mm},(c) 0.96 \mathrm{~mm},(d) 0.48 \mathrm{~mm},(e) 0.24 \mathrm{~mm}$, and (f) $0.12 \mathrm{~mm}$ scale 


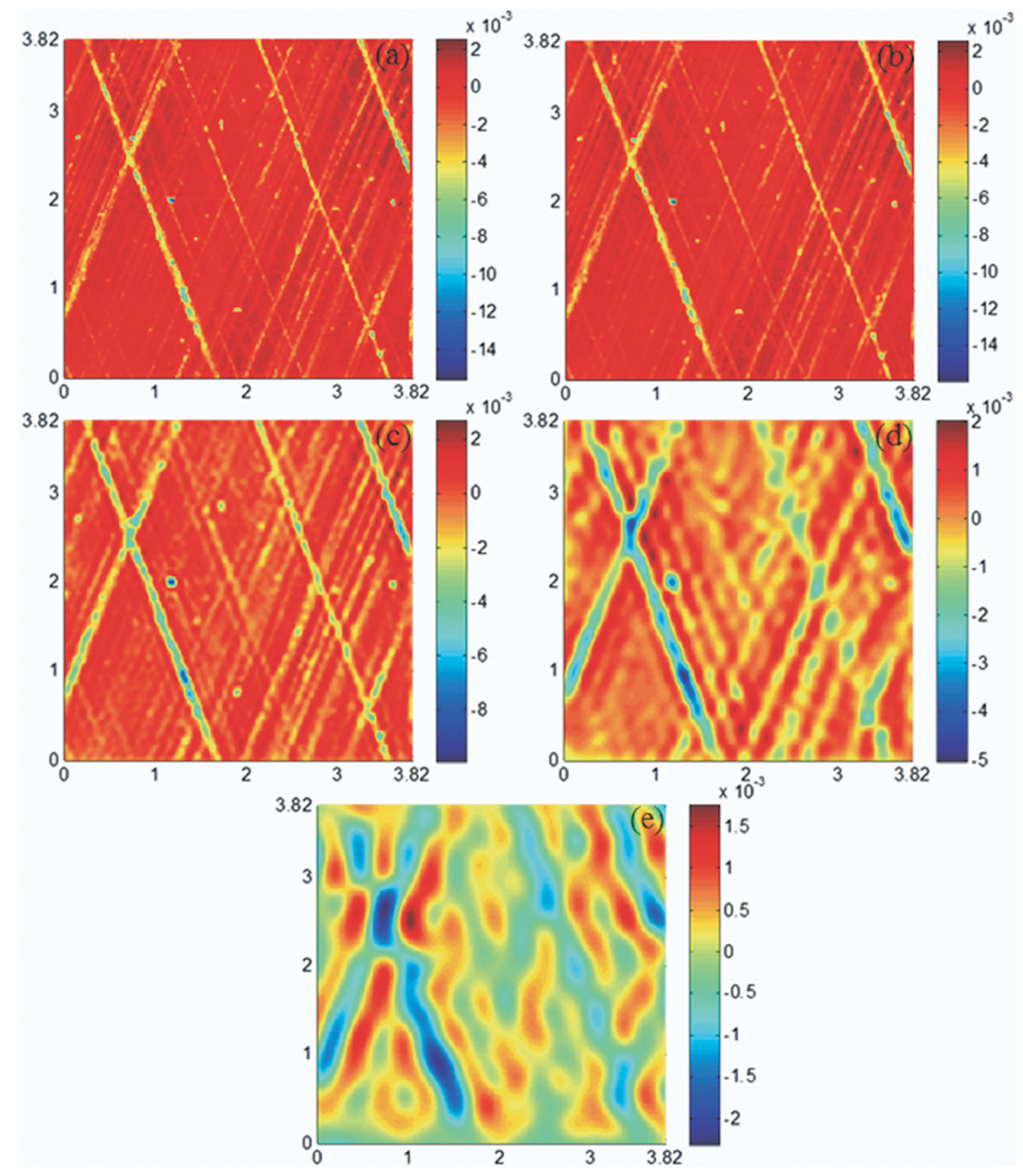

Fig. 3 Honed surface with different finer scale limit (a) original plateau-honed surface and surface after removing (b) $0.12 \mathrm{~mm}$ scale, (c) $0.24 \mathrm{~mm}$ scale, (d) $0.48 \mathrm{~mm}$ scale, and (e) $0.96 \mathrm{~mm}$ scale

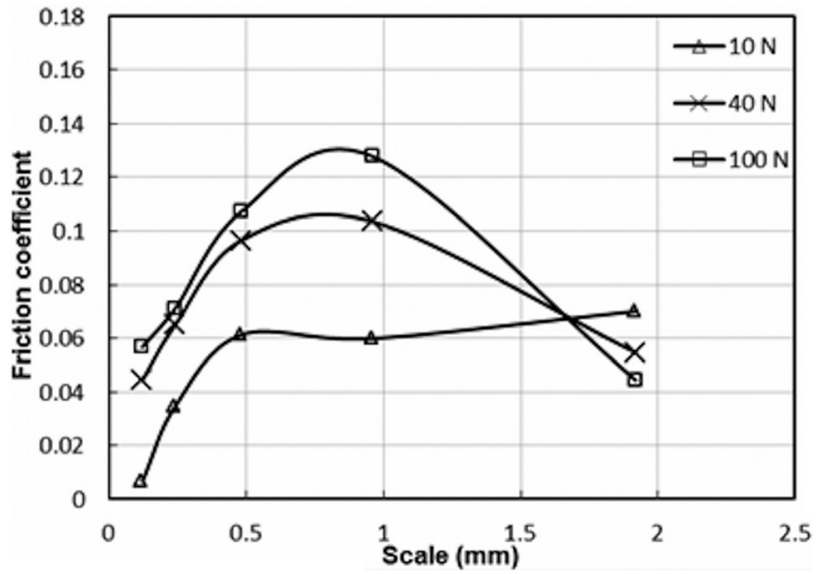

Fig. 4 Fiction coefficient as a function of scale for $u_{1}=2 \mathrm{~m} \cdot \mathrm{s}^{-1}$ and (a) $\operatorname{Srr}=2.0$
$100 \%$ represents dry contact. Figure 5 depicts the contact load ratio in percent as a function of the scale. The friction increases with the contact load ratio. These results are in agreement with the fact that the coefficient of friction is sensitive to asperity area fraction [32]. For $10 \mathrm{~N}$, the contact load ratio is relatively small. The finer roughness scale plays a benefic rule. Indeed, the friction coefficient is relatively high for smooth surfaces represented by a high scale, whereas for a low scale, the friction coefficient is small. The addition of small surface scales is characterized by an increase of asperities. The small asperities could produce microhydrodynamic bearing, which generates additional hydrodynamic pressure to increase the load carrying capacity and improve the friction coefficient. This mechanism occurs at $0.96 \mathrm{~mm}$ scale. For $40 \mathrm{~N}$, the contact load ratio increase to a relatively high value and decrease after the addition of $0.96 \mathrm{~mm}$ scale. The value corresponds to the scale at which the transition occurs. Microroughness has a beneficial rule. For $100 \mathrm{~N}$, the same behavior is observed (two transitions). However, transition from mixed lubrication to full-film occurs at $0.48 \mathrm{~mm}$ scale. We can, nevertheless, consider $0.96 \mathrm{~mm}$ scale as transition value. Indeed, an improvement is observed on friction coefficient in this scale (Fig. 4). According to the results, there exists a scale at which roughness becomes 


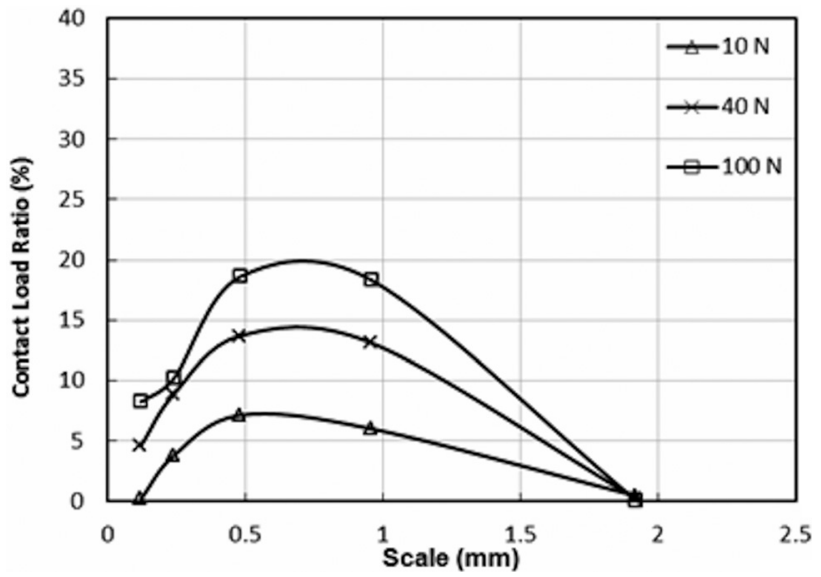

Fig. 5 Contact load ratio as a function of scale for $u_{1}=2 \mathrm{~m} \cdot \mathrm{s}^{-1}$ and $S r r=2.0$

beneficial for a given load. For this case, the $0.96 \mathrm{~mm}$ scale is beneficial. The degradation of friction coefficient between 1.92 and $0.96 \mathrm{~mm}$ scale is probably due to the addition of asperities. These asperities are large enough to "break" the lubricant resulting in a mixed lubrication. For the fine scale (second transition), asperities is characterized by small size (microroughness). These microroughnesses generate microhydrodynamic bearing, increasing the load carrying capacity. Such additional load improves the friction coefficient.

To understand if the benefic rule of roughness is observed always at the same scale, a more severe case was used. A velocity of $0.5 \mathrm{~m} \cdot \mathrm{s}^{-1}$ is used for the same load. Figure 6 depicts the friction coefficient as a function of the scale. For low load $(10 \mathrm{~N})$, the same behavior is observed: a decrease of friction coefficient when scale decreases. However, the level of the friction coefficient is higher with low velocity. This observation is in agreement with the fact that the sliding speed of textured surface brings additional flow into the interface and enhances the film thickness [33]. The second difference is the roughness scale at which friction reduction occurs: $0.48 \mathrm{~mm}$. For $40 \mathrm{~N}$ and $100 \mathrm{~N}$, the friction coefficient increases until a scale of $0.48 \mathrm{~mm}$ and then decreases. However, the increase of friction coefficient is more important for $100 \mathrm{~N}$ than for $40 \mathrm{~N}$. At the medium scale $(0.98 \mathrm{~mm}$ to $0.48 \mathrm{~mm})$, lubrication transits from mixed to boundary and friction coefficient increase. Adding asperities deteriorate the friction coefficient for high load. Figure 7 justifies this trend. Contact load ratio increases until a maximum value $(37 \%)$ with the decrease of scale. At finer

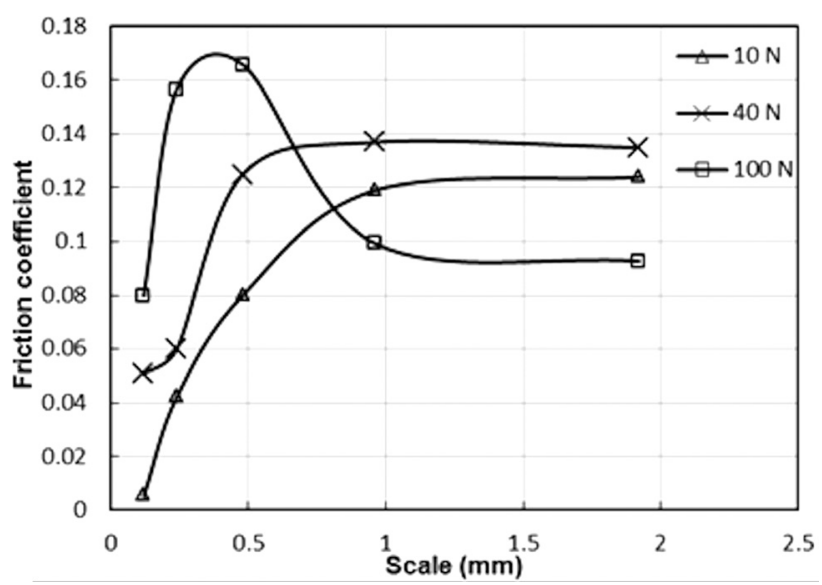

Fig. 6 Fiction coefficient as a function of scale for $u_{1}=0.5 \mathrm{~m} \cdot \mathrm{s}^{-1}$ and $S r r=2.0$

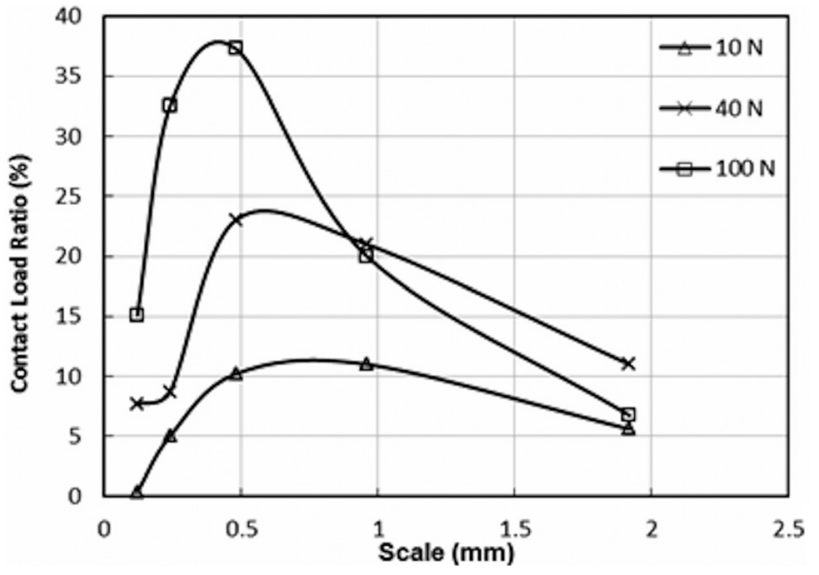

Fig. 7 Contact load ratio as a function of scale $u_{1}=0.5 \mathrm{~m} \cdot \mathrm{s}^{-1}$ and $\operatorname{Srr}=\mathbf{2 . 0}$

scale, an improvement in friction coefficient is observed for 40 and $100 \mathrm{~N}$. This amelioration starts with the $0.48 \mathrm{~mm}$ scale. As for $10 \mathrm{~N}$, this scale is beneficial for friction reduction.

This change of behavior of friction as well as the contact load ratio could be explained by microhydrodynamic bearing, which generates additional hydrodynamic pressure to increase the load carrying capacity.

The finer surface irregularities could improve the friction coefficient for a relatively severe contact (high load, low velocity). Thus, the use in a honing process of finer abrasive grits - to generate finer surface irregularities-will have a beneficial effect on the friction, as demonstrated in Ref. [55]. For relatively high velocity, more roughness scale is activated and multiscale surface texture has a greater impact on the friction.

For an in-depth study of the effect of finer scale on the friction coefficient at severe contact conditions, the rough surface must be acquired at higher resolution and decomposed into more roughness scale. In addition, simulation can be done with more severe contact conditions, which would be the subject of future research.

\section{Conclusions}

The present study is aimed at understanding the influence of the roughness scale on the friction coefficient by means of numerical simulations in lubricated point contacts. For this purpose, a numerical simulation using surfaces with different roughness wavelength bandwidths was conducted. These surfaces were obtained from an original surface decomposed at different scales from waviness to roughness by a multiscale ridgelet transform. The following conclusions can be drawn from the results:

- For a relatively high velocity, the friction coefficient increases and decreases at a given scale for all loads. However, for relatively high load (40 and $100 \mathrm{~N})$, a transition from full-film to mixed lubrication occurred. The fine roughness scale improves the friction coefficient event at mixed lubrication. This improvement occurs at scale $0.96 \mathrm{~mm}$, whatever the load. This could be explained by the microhydrodynamic bearing, which generates additional hydrodynamic pressure to increase the load carrying capacity.

- For a relatively low velocity, the friction coefficient increases when scale decreases to attain mixed lubrication value: transition from full-film and the mixed lubrication is also shown for moderate load. For high load $(100 \mathrm{~N})$, lubrication transits from full-film to mixed (scale from $1.92 \mathrm{~mm}$ to $0.96 \mathrm{~mm}$ ) and from mixed to boundary (scale from $0.96 \mathrm{~mm}$ to $0.48 \mathrm{~mm}$ ). However, at fine scale (i.e. $0.48 \mathrm{~mm}$ ) the friction coefficient is improved. Again, fine roughness scale improves the lubrication. 


\section{Acknowledgment}

The authors thank Sylvain Legros for his dedication and computer support during this work.

\section{Nomenclature}

$a=$ scale parameter, $\mathrm{m}$

$a_{h}=$ Hertzian contact radius, $\mathrm{m}$

$b=$ translation coefficient, $\mathrm{m}$

$F_{N}=$ external applied load, $\mathrm{N}$

$h=$ film thickness, $\mathrm{m}$

$H=$ dimensionless film thickness

$H_{0}=$ dimensionless rigid body displacement

$M, L=$ Moes dimensionless parameters

$p_{h}=$ Hertzian pressure, $\mathrm{Pa}$

$p_{r}=$ constant, $p_{r}=1.96 .10^{8} \mathrm{~Pa}$

$p=$ pressure, $\mathrm{Pa}$

$P=$ dimensionless pressure

$R_{x} R_{y}=$ radius of curvature in $x$ and $y$ direction, respectively, $\mathrm{m}$

$R=$ equivalent radius of curvature, $\mathrm{m}$

$S r r=$ slide to roll ratio: $\operatorname{Srr}=2\left(u_{1}-u_{2}\right) /\left(u_{1}+u_{2}\right)$

$T=$ time, $\mathrm{s}$

$T=$ dimensionless time: $T=t u_{m} / \mathrm{a}_{h}$

$u_{i}=$ velocity of surface $I, \mathrm{~m} \cdot \mathrm{s}^{-1}$

$u_{m}=$ mean velocity, $\left(u_{1}+u_{2}\right) / 2, \mathrm{~m} \cdot \mathrm{s}^{-1}$

$x, y, z=$ space coordinates, $\mathrm{m}$

$X, Y, Z=$ dimensionless space coordinates

$Z_{r}=$ pressure viscosity index (Roelands), $Z_{r}=p_{r} \alpha /$ $\left(\ln \left(\eta_{0}\right)+9.67\right)$

$Z_{h}=$ height surface topography, $\mathrm{m}$

\section{Greek Symbols}

$\alpha=$ pressure-viscosity coefficient, $\mathrm{Pa}^{-1}$

$\delta=$ elastic deflection of the contacting bodies, $\mathrm{m}$

$\bar{\delta}=$ dimensionless elastic deflection of the contacting bodies

$\bar{\eta}=$ effective viscosities, dimensionless

$\theta=$ angle, $\mathrm{rad}$

$\mu=$ viscosity, $\mathrm{Pa} \cdot \mathrm{s}$

$\bar{\mu}=$ dimensionless viscosity

$\mu_{0}=$ ambient temperature zero-pressure viscosity, Pa.s

$\bar{\rho}=$ dimensionless lubricant density

$\rho_{0}=$ ambient temperature and pressure density, $\mathrm{kg} \cdot \mathrm{m}^{-3}$

$\tau_{e}=$ equivalent shear stress, $\mathrm{Pa}$

$\tau_{0}=$ characteristic shear stress of Eyring fluid, $\mathrm{Pa}$

$\overline{\tau_{m}}=$ dimensionless mean shear stress

\section{References}

[1] Dowson, D., and Higginson, G. R., 1966, Elastohydrodynamic Lubrication, The Fundamentals of Roller and Gear Lubrication, Pergamon, Oxford, UK.

[2] Hamrock, B., and Dowson, D., 1977, "Isothermal Elastohydrodynamic Lubrication of Point Contacts, Part III-Fully Floded Results," ASME J. Lubr. Technol., 99, pp. 264-276.

[3] Spikes, H. A., 1999, "Thin Films in Elastohydrodynamic Lubrication: The Contribution of Experiment," Proc. Inst. Mech. Eng. Part J: J. Eng. Tribol., 213, pp. 335-352.

[4] Kaneta, M., and Kishikawa H., 1999, "Experimental Study on Microelastohydrodynamic Lubrication," Proc. Inst. Mech. Eng. Part J: J. Eng. Tribol., 213, pp. 371-382.

[5] Lubrecht, A. A., and Venner, C. H., 1999, "Elastohydrodynamic Lubrication of Rough Surfaces," Proc. Inst. Mech. Eng. Part J: J. Eng. Tribol., 213, pp. 397-404.

[6] Jacobson, B., and Hamrock, B. J., 1984, "Non-Newtonian Fluid Model Incorporated into Elastohydrodynamic Lubrication of Rectangular Contacts," ASME J. Tribol., 106(2), pp. 275-284.

[7] Sui, P. C., and Sadeghi, F., 1991, "Non-Newtonian Thermal Elastohydrodynamic Lubrication,” ASME J. Tribol., 113(2), pp. 390-3973.

[8] Conry, T. F., Wang, S., and Cusano, C., 1987, "A Reynolds-Eyring Equation for Elastohydrodynamic Lubrication in Line Contacts," ASME J. Tribol., 109(4), pp. 648-658.

[9] Kim, K. H., and Sadeghi, F., 1991, "Non-Newtonian Elastohydrodynamic Lubrication of Point Contacts," ASME J. Tribol., 113(4), pp. 703-711.

[10] Evans, C. R., and Johnson, K. L., 1986, "Regimes of Traction in Elastohydrodynamic Lubrication," Proc. Inst. Mech. Eng., Part C: J. Mech. Eng. Sci., 200, pp. 313-324.
[11] Olver, A., and Spikes, H. A., 1998, "Prediction of Traction in Elastohydrodynamic Lubrication," Proc. Inst. Mech. Eng., Part J: J. Eng. Tribol., 212, pp. 321-332.

[12] Jacod, B., Venner, C. H., and Lugt, P. M., 2001, "A Generalized Traction Curve for EHL Contacts," ASME J. Tribol. 123(2), pp. 248-253.

[13] Jacod, B., Venner, C. H., and Lugt, P. M., 2004, "Influence of Longitudinal Roughness on Friction in EHL Contacts," ASME J. Tribol. 126(3), pp. 473-481.

[14] Patir, N., and Cheng, H. S., 1978, "An Average Flow Model for Determining Effects of Three-Dimensional Roughness on Partial Hydrodynamic Lubrication," ASME J. Lubr. Technol., 100, pp. 12-17.

[15] Tripp, J. H., 1983, "Surface Roughness Effetcs in Hydrodynamic Lubrication: The Flow Factor Method," ASME J. Lubr. Technol., 105, pp. 458-465.

[16] Kim, T. W., and Cho, Y. J., 2007, "The Flow Factors Considering the Elastic Deformation for the Rough Surface With a Non-Gaussian Height Distribution," Tribol. Trans., 51, pp. 213-220.

[17] Goglia, P. R., Cusano, C., and Conry, T. F., 1984, "The Effects of Irregularities on the Elastohydrodynamic Lubrication in Sliding Line Contacts: Part ISingle Irregularities," ASME J. Tribol., 106(1), pp. 104-112.

[18] Greenwood, J. A., and Johnson, K. L., 1992, "The Behaviour of Transverse Roughness in Sliding Elastohydrodynamic Lubricated Contacts," Wear, 153, pp. 107-117.

[19] Morales-Espejel, G. E., 1993, "Elastohydrodynamic Lubrication of Smooth and Rough Surface," Ph.D. thesis, University of Cambridge, Cambridge, UK.

[20] Venner, C. H., 1991, "Muiltilevel Solution of EHL Line and Point Contact Problems," Ph.D. thesis, University of Twente, Enscheden, The Netherlands.

[21] Hooke, C. J., 1998, "Surface Roughness Modification in Elasto-Hydrodynamic Operating in thee Elastic Piezoviscous Regime," Proc. Inst. Mech. Eng. Part J: J. Eng. Tribol., 212, pp. 145-162.

[22] Hooke, C. J., 1999, "Surface Roughness Modification in EHL Line ContactsThe Effects of Roughness Wavelength, Orientation and Operating Conditions," Proceedings of the Leeds-Lyon Symposium on Tribology, pp. 193-202.

[23] Venner, H. C., and Lubrecht, A. A., 1999, "Amplitude Reduction of Non-Isotropic Harmonic Patterns in Circular EHL Contacts Under Pure Rolling," Proceedings of the Leeds-Lyon Symposium on Tribology, pp. $151-162$.

[24] Chapkov, A., 2006, "Etude des Contacts Elastohydrodynamique Lubrifiés Avec un Fluide Non-Newtonien," Ph.D. thesis, INSA de Lyon, Lyon, France.

[25] Riche, I., and Villechaise, B., 2004, "Etude de la Lubrication EHD Rugueuse Etablie Localement dans un Palier," Mech. Ind., 5, pp. 677-684.

[26] Elrod, H. G., 1973, "Thin-Film Lubrication Theory for Newtonian Fluids With Surfaces Processing Started Roughness or Grooving," ASME J. Lubr. Technol., 95, pp. 484-489.

[27] Bayada, G., and Chambat, M., 1988, "New Models in the Theory of the Hydrodynamic Lubrication of Rough Surfaces," ASME J. Tribol., 110(3), pp. 402-407.

[28] Bayada, G., Martin, S., and Vazquez, C., 2005, "An Average Flow-Model of the Reynolds Roughness Including a Mass-Flow Preserving Cavitation Model," ASME J. Tribol., 127(4), pp. 793-802.

[29] Buscaglia, G., and Jaï, M., 2000, "A New Numerical Scheme for Non Uniform Homogenized Problems: Application to the Non Linear Reynolds Compressible Equation," Math. Probl. Eng., 7, pp. 355-378.

[30] Kane, M., and Bou-Said, B., 2004, "Comparison of Homogenization and Direct Techniques for the Traeatment of Roughness in Incompressible Lubrication," ASME J. Tribol., 126(4), pp. 733-737.

[31] Etsion, I., 2005, "State of the Art in Laser Surface Texturing," ASME J. Tribol. 127(1), pp. 248-253.

[32] Siripuram, R. B., and Stephens, L. S., 2004, "Effect of Deterministic Asperity Geometry on Hydrodynamic Lubrication," ASME J. Tribol., 126(3), pp. 527-534.

[33] Nanbu, T., Ren, N., Yasuda, Y., Zhu, D., and Wang, Q. J., 2007, "Micro Textures in Concentrated Conformal-Contact Lubrication: Effects of Texture Bottom Shape and Surface Relative Motion," Tribol. Lett., 29, pp. 241-252.

[34] Kovalchenko, A., Ajayi, O., Erdemir, A., Fenske, G., and Etsion, I., 2005, "The Effect of Laser Surface Texturing on Transitions in Lubrication Regimes During Unidirectional Sliding Contact," Tribol. Int., 38, pp. 219-225.

[35] Ajayi, O. O., Erck, R. A., Lorenzo-Martin, C., and Fenske, G. R., 2009 "Frictional Anisotropy Under Boundary Lubrication: Effect of Surface Texture," Wear, 267, pp. 1214-1219.

[36] Martini, A., Zhu, D., and Wang, Q., 2007, "Friction Reduction in Mixed Lubrication," Tribol. Lett., 28, pp. 139-147.

[37] Wang, W., Wang, S., Shi, F., Wang, Y., Chen, H., Wang, H., and Hu, Y., 2007, "Simulations and Measurement of Sliding Friction Between Rough Surfaces in Point Contacts: From EHL to Boundary Lubrication,” ASME J. Tribol., 129(3), pp. 495-501.

[38] Demirci, I., Mezghani, S., Yousfi, M., Zahouani, H., and El Mansori, M., 2012, "The Scale Effect of Roughness on Hydrodynamic Contact Friction," Tribol. Trans., 55(5), pp. 705-712.

[39] Mezghani, S., Demirci, I., Zahouani, H., and El Mansori, M., 2012, "The Effect of Groove Texture Patterns on Piston-Ring Pack Friction," Precis. Eng., 36(2), pp. 210-217.

[40] Najji, B., Bou-Said, B., and Berthe, D., 1989, "New Formulation for Lubrication With Non-Newtonian Fluids," ASME J. Tribol., 111(1), pp. 29-33.

[41] Roelands, C. J. A., 1966, "Correlational Aspects of the Viscosity-Temperature-Pressure Relationships of Lubricant Oil," Ph.D. thesis, Technische Hogeschol Delft, Delft, The Netherlands. 
[42] Venner, C. H., and Morales-Espejel, G. E., 1999, "Amplitude Reduction of Small-Amplitude Waviness in Transient Elastohydrodynamically Lubricated Line Contacts," Proc. Inst. Mech. Eng. Part J: J. Tribol., 213, pp. 487-504.

[43] Venner, C. H., and Lubrecht, A. A., 2000, Multilevel Methods in Lubrication, Elsevier, The Netherlands.

[44] Hu, Y. Z., and Zhu, D., 2000, "A Full Numerical Solution to the Mixed Lubrication in Point Contacts," ASME J. Tribol., 122(1), pp. 1-9.

[45] Ren, N., Zhu, D., Chen, W. W., and Wang, Q. J., 2010, "Plasto-Elastohydrodynamic Lubrication (PEHL) in Point Contacts," J. Tribol., 132, p. 031501 .

[46] Chapkov, A., Venner, C. H., and Lubrecht, A. A., 2006, "Roughness Amplitude Reduction Under Non-Newtonian EHD Lubrication Conditions," ASME J. Tribol., 128(4), pp. 753-760.

[47] Zahouani, H., Mezghani, S., Vargiolu, R., and Dursapt M., 2008, "Identification of Manufacturing Signature by 2D Wavelet Decomposition," Wear, 264(5-6), pp. $480-485$.

[48] El Mansori, M., Mezghani, S., Sabri, L., and Zahouani, H., 2010, "On Concept of Process Signature in Analysis of Multistage Surface Formation," Surf. Eng., 26(3), pp. 216-223.
[49] Mezghani, S., Zahouani, H., and Piezanowski, J. J., 2011, "Multiscale Characterizations of Painted Surface Appearance by Continuous Wavelet Transform,"' J. Mater. Process. Technol., 211(2), pp. 205-211.

[50] Mezghani, S., Sura, E., and El Mansori, M., 2008, "The Effect of Belt Finishing Process Variables on the Topography of Finished Surface," Tribol. Trans., 51(4), pp. 413-421.

[51] Demirci, I., Mezghani, S., Mkaddem, A., and El Mansori, M., 2010, "Effects of Abrasive Tools on Surface Finishing Under Brittle-Ductile Grinding Regime When Manufacturing Glass," J. Mater. Process. Technol., 210(3), pp. 466-473.

[52] Xin, B., 2009, "Multiscale Analysis of Rough Groove Textures for ThreeDimensional Optical Measurements," Opt. Eng., 48(7), p. 073602.

[53] Candès, E. J., and Guo, F., 2002, "New Multiscale Transforms, Minimum Tota Variation Synthesis: Applications to Edge-Preserving Image Reconstruction," Signal Process., 82(11), pp. 1519-1543.

[54] Rabinowicz, E., 1980, "Friction-Especially Low Friction," Proceedings of the International Conference on the Fundamentals of Tribology, N. P. Suh and N. Saka, eds., The MIT Press, Cambridge, MA, pp. 351-364.

[55] Sabeur, M., Ibrahim, D., Hassan, Z., and Mohamed, E. M., 2013, "Energy Efficiency Optimization of Engine by Frictional Reduction of Functional Surfaces of Cylinder Ring-Pack System," Tribol. Int., 59, pp. 240-247. 